\title{
Pranayama and Breathing Exercises - Types and Its Role in Disease Prevention \& Rehabilitation
}

\author{
Naresh Kumar Satyanarayan Dhaniwalaํㅡ, Venkatesh Dasari², Mukunda Naresh Dhaniwala ${ }^{3}$
}

1,2 Department of Orthopaedics, Jawaharlal Nehru Medical College, DMIMS, Sawangi, Wardha, Maharashtra, India. ${ }^{3}$ Department of Orthopaedics, Mahatma Gandhi Institute of Medical College, Sciences, Sawangi, Wardha, Maharashtra, India.

\section{ABSTRACT}

Yoga is a multi-faceted spiritual tool enhancing health and well-being. Physical postures (Asan), regulated breathing (Pranayama), and meditations (Dhyana) are its main components. Breathing exercises of various types, particularly diaphragmatic breathing, alternate nostril breathing (anulom vilom), and kapalbhati have been noted to be useful in chronic asthma, chronic obstructive pulmonary disease (COPD), gastroesophageal reflux disease (GERD), post-operative management in head \& neck surgery, cardiovascular surgery, and upper abdominal surgery. Its calming effect reduces blood pressure and agitation in various psychiatric disorders also. Common types of breathing exercises which are easy to learn and practice for day to day fitness and prevention of disease are: equal breathing (bhastrika), clavicular breathing, costal breathing, and diaphragmatic breathing. kapalbhati, alternate nostril breathing (anulom vilom), bhramari pranayama, and tribandh breathing. These require proper learning under guidance. Ujjayi pranayama, sitali, and surya bhedan pranayama also require proper training and have a calming effect on the body. Various types of breathing produce their beneficial effects on the body when they are done regularly for the minimum recommended period. These exercises can be practiced in any comfortable posture on the floor or sitting on a chair. Regulation of rate and rhythm during its practice helps towards achieving meditation. Pranayama and Yoga have proven their utility in various diseases as noted in studies done in various medical centers. The western world also recognizes its importance and recommends it to their people. In India, health is given a low priority and outdoor physical activities are becoming less popular. In these conditions of living, Yoga and Pranayama (breathing exercises) are recommended for persons of all ages because these are easy to learn, simple to practice, and do not require any separate space or instruments. Regularity and execution in a proper way for the optimum time alone are needed for general well-being, better lung functions, and as a preventive measure for various respiratory and psychiatric disorders. In the present pandemic of COVID19 , warranting house quarantine for a large number of people, this is going to prove a boon for physical and mental alleviation.

\section{KEY WORDS}

Pranayama, Breathing Exercises, Disease, Prevention

\begin{abstract}
Corresponding Author: Dr. Venkatesh Dasari. Department of Orthopedics, Jawaharlal Neharu Medical College, DMIMS, Sawangi, Wardha-492001, Maharashtra, India. E-mail:vdasari158@gmail.com
\end{abstract}

DOI: $10.14260 / \mathrm{jemds} / 2020 / 730$

How to Cite This Article: Dhaniwala NS, Dasari V, Dhaniwala MN, et al. Pranayama and breathing exercises types and its role in disease prevention \& rehabilitation. J Evolution Med Dent Sci 2020;9(44):3325-3330,

$10.14260 /$ jemds $/ 2020 / 730$

Submission 21-07-2020,

Peer Review 24-09-2020,

Acceptance 30-09-2020,

Published 02-11-2020.

Copyright (c) 2020 Naresh Kumar Satyanarayan Dhaniwala et al. This is an open access article distributed under Creative Commons Attribution License [Attribution 4.0 International (CC BY 4.0)] 


\section{BACKGROUND}

Proper nutrition of the body is necessary for the development and growth of body and mind. An infant if fed properly with nutritious food in the required amount grows to become a healthy adult with a positive state of physical, mental, and social well-being. An undernourished child, on the other hand, may develop multiple diseases and negative feelings. The importance of nutrition in disease prevention has been highlighted in many studies. ${ }^{1}$ Healthy family and social environment is needed to develop a positive mental and social well-being. Physical Exercises similarly have a significant role in the development of body and mind in human beings. Exercises not only help in the growth of a child, but these also keep internal body organs in a fully functional state. Besides, exercises prevent the onset of many diseases and help in rehabilitation in orthopaedic, neurological and post-operative conditions. Exercises could be of multiple types. Swimming, cycling, team sports, brisk walking, running and athletics, aerobics, triathlon, high intensity interval training, specific muscle strengthening and stretching, muscle contraction, joint mobilization etc. are some examples of exercises. Gymnastic training, tread mill walking, various individual sports, skiing, surfing are other forms of exercises. Many exercises are adventurous in nature while others are targeting at specific objective of body building, muscle strengthening or joint mobilization.

Thousands of years ago yoga originated in India, and in the present day and age, an alarming awareness has been observed in health and natural remedies among people for yoga and pranayama. Yoga has proved to be an effective method for improving health in addition to prevention and management of diseases. Yoga includes its various physical postures known as Asanas, breathing patterns better identified as Pranayama and meditation or Dhyana. Yoga has emerged as a useful tool for lay persons and sick persons. Though known in India for many centuries, it has spread like a fast storm after its benefits were popularized and number of demonstration camps were organized to teach various Asanas and Pranayama including breathing exercises. All its aspects need proper training and involvement for getting its maximum benefit.

Pranayama and other breathing exercises have gained more importance these days due to its definite role in improving blood oxygenation and utilization of the greater capacity of lungs, thereby helping in the prevention of many diseases. Pranayama is an art consisting of techniques to make the respiratory organs to move and expand intentionally, rhythmically, and intensely. It consists of the long, sustained subtle flow of atmospheric air (inhalation / puraka) into the lungs, the outflow of deoxygenated air from lungs to the atmosphere (exhalation / recheka), and retention of breath in between (kumbhaka). As per yoga, inhalation stimulates the body system, causes inflow of oxygenated air through the nostrils into the lungs. Exhalation throws out the deoxygenated air and makes the lungs ready to receive fresh air. kumbhaka (holding breath) distributes the energy through the body by permitting the oxygenated air to transfer its oxygen into the blood. Thus inhalation, holding the breath and exhalation are the three basic steps of yogic breathing exercises. Normally inhalation and exhalation are done for the equal time while breath hold is for twice the duration of inspiration or expiration. In the present days, breath holding step has been taken out, thereby making breathing cycle consisting of only inspiration and exhalation. During Pranayama lungs and the rib cage (thorax) undergo horizontal expansion (dairghya), vertical ascension (aroha), and circumferential expansion (vishalata). This ensures expansion of both the lungs in all its lobes in the front as well as back aspect.

Proper breathing helps oxygenation of blood, removal of carbon dioxide thereby mental concentration, good health, and longevity. It provides oxygen to the cells of various organs including brain, heart and kidney. Oxygen gives life to the cells and keeps them alive. That is the reason air is known as pranvayu, giving life to the human body. Breathing exercises have probably been labelled as Pranayama, as these are responsible for providing the life energy to our body. Breathing exercises are useful not only in maintaining good health and prevention of various systemic diseases, they keep us alert, active and socially compatible and maintain a positive state of physical, mental, social wellness. Exercises have been studied extensively regarding their role in different medical diseases. Its role in asthma, chronic obstructive pulmonary diseases, systemic hypertension, post-operative management in general surgery, cardiovascular surgeries, and head and neck surgeries has been documented. $2,3,4,5,6,7,8,9$ Yoga has been noted to improve visual, mental and neurological functions also. The article attempts to outline various types of breathing exercises and their role in overall human well- being.

\section{BREATHING EXERCISES AND ITS TYPES}

Breathing exercises should normally be done in a sitting and comfortable position of lower limbs, either in 'padmasana' or 'vajrasana' or in sitting cross-legged position. In case of hip and knee joint diseases causing difficulty in sitting cross-legged or extreme flexed position, one can do these while sitting on a chair. One should be sitting comfortably with erect spine. Breathing exercises should not be done after meals and at least an interval of three hours should elapse between the last meal and exercises. Preferred time is early morning after bowel emptying or a minimum of three hours after meals. Exercises should be learned properly and chosen each type should be done at least 5 - 10 times in the beginning, which can be increased gradually every week.

Based on the Indian Yoga concepts, breathing exercises can be classified in the following types -

\section{Normal / Natural Breathing}

It is the naturally and involuntarily occurring breathing in which mostly the inspiration time exceeds the expiration time. It can also be called as quiet breathing as it continues to occur at all times during the life of a person without any sound production or voluntary effort. It mostly utilizes the abdomen and moves diaphragm for inhalation and exhalation. Its normal rate is $12-16$ / minute. In cases of chronic pulmonary disease, it may become shallow and slower. In a normal healthy person chest expansion on full inspiration should be $5 \mathrm{~cm}$. In diseases of the lungs and chest this expansion becomes reduced. In ankylosing spondylitis due to involvement of costo-vertebral joints, 
chest expansion becomes reduced up to $2 \mathrm{~cm}$. Normal breathing becomes laboured when there is gross decrease in oxygen supply. Most of the times it changes to gasping in the terminal stages of a fatal disease. At the gasping stage, accessory muscles of respiration such as neck muscles come in action. In COPD cases also neck muscles may be used for normal respiration.

\section{Equal Breathing}

It is the type of breathing in which the inspiration and expiration phase take equal time in the respiration cycle. Actually, it is improved version of the normal breathing. It is important to practice this because it ensures the removal of total carbon-dioxide from the lungs before starting new inspiration. In normal breathing, many among us inspire for a longer duration than the time for expiration, thereby leaving a part of the lung filled with deoxygenated air which in turn reduces the amount of air inhaled. bhastrika (bellow's breath) is a special type of equal breathing in which short, sharp, even inhales and exhales are done through the nose. It may sound like a dog panting when done fast and continuously. It is initially done voluntarily, but later may become natural for the person. For beginners, it is best to inhale fresh air deeply to a count of three and then slowly exhale it to a count of further three, making it 4, 5 and 6 . This should be repeated at least 10 times in a slow and rhythmic manner. Among breathing exercises, this is mostly done as the starting exercise.

\section{Thoracic Breathing}

It is the type of breathing in which thoracic (intercostal) muscles are used more than the diaphragm. It is a component of a normal breathing cycle but may need extra effort by a sedentary individual. This type involves action of 12 pairs of ribs along with its attached intercostal muscles. During inhalation ribs move superiorly and anteriorly, and go back inferiorly and posteriorly in exhalation. It mostly comes in its full role after physical activities like running, skipping, and outdoor games due to increased oxygen requirements. In cases of cervical spine injury, intercostal muscles may stop functioning due to paralysis and the patient's respiration primarily becomes abdominal. In COPD and Ankylosing spondylitis, this is primarily affected. In the paralysis of diaphragmatic and thoracic muscles, the patient starts using accessory neck muscles for breathing. Depending on the part of thorax being primarily used in breathing, thoracic breathing can be sub-classified into:

\section{- Clavicular Breathing}

It is the type of breathing in which the upper part of thorax (clavicular / apical area of lungs) is voluntarily put into action to help lung's expansion and contraction in respiration. It can be assessed by measuring the expansion of this area by tape. Alternatively, one can keep his both open hands on the upper chest, finger tips touching in the sternal area and assessing expansion by the increase in distance between fingers. This breathing may be decreased in apical lobe involvement in pneumonia or tuberculosis.

\section{- Costal Breathing}

It is the thoracic breathing utilizing primarily the middle part of thorax with the efforts of intercostal muscles. This is involved in generalized lung disease, pneumonia, silicosis and similar occupation related pulmonary conditions. Its extent can also be measured by tape or noting the expansion by digital distancing. It refers to normal breathing site in laymen language. This is also seen to be occurring to a deficient degree, as many persons use neck muscles instead of intercostal muscles. This causes a superior and inferior movement of the chest instead of outward and transverse expansion of the chest.

\section{Abdominal (Diaphragmatic) Breathing}

It is the type of breathing utilizing the diaphragm primarily. Diaphragm is the involuntary muscle separating chest cavity from the abdomen. Its contraction causes flattening, thereby air enters the lungs. Its relaxation, on the other hand causes dome shape formation of the muscle, by which deoxygenated air is expelled out of the lungs. During inhalation contraction of diaphragm causes downward and outward movement of the abdomen, while during exhalation, the abdomen comes upwards and inwards. This type of breathing causes the expansion and contraction of all the parts of both the lungs in all directions and is important for maintaining the vital capacity to the maximum.

Kapalabhati is an advanced yogic diaphragmatic breathing technique that increases the lungs' capacity and oxygenates the mind and body. It helps release negative emotions, shakes off sluggishness, and energizes the person. It can be done in a sitting position with a relaxed body. It can also be done in supine position with both hips and knee flexed and hand kept on right upper abdomen to assess the movement. It primarily consists of active and forceful exhalation using abdominal muscles and passive inhalation. Its utility in various disease conditions such as atelectasis and COVID-19 has been documented.7,10 Diaphragmatic breathing helps in the total health of the person by full and rhythmic contraction of diaphragm. It is supposed to be of great help when done at least for 10 minutes every day. Initially it may be done for $2-3$ minutes and then gradually increased to $10-15$ minutes. Normally, a healthy person can do $60-70$ voluntary exhalation with similar spontaneous involuntary inspirations occurring in one minute. Nearly 300 strokes can be done in 5 minutes. Kapalbhati has been found to help in mild to moderate COVID 19 patients. It has been associated with slow weight loss in many persons on regular practice. It is a strenuous exercise utilizing good amount of energy.

\section{Deep Breathing}

It is the breathing in which inspiration and expiration are repeated after longer intervals in each cycle. It makes the breathing pattern slow, long, and deep. It helps in more utilization of the vital capacity of lungs and instils a feeling 
of calmness in the person. Deep breathing may be done in ratios, thereby prolonging inspiration or expiration time in relation to each other.

\section{Fast (Quick) Breathing}

It is the opposite of the deep breathing. In this inspiration and expiration are done for a shorter duration in a fast manner. It is used in certain types of breathing such as anulom vilom. Quick breathing can also be done with either left nostril or right nostril alone.

7. Alternate Nostril Breathing (Anulom Vilom or Nadi Shodhan Pranayam)

It is the special type of breathing cycle involving alternate nostril, and gets commenced after expelling air forcefully from one nostril from which inspiration is to commence. For example, if inhalation is done from the right nostril, the left nostril is kept closed. After full inhalation, the right nostril is closed and the air is expelled from the left nostril. After a full exhalation, now inhalation is done again from the left nostril, and exhalation from the right nostril, after closing the left nostril. Thus, in any action of inhalation or exhalation, only one nostril is used. Air is inhaled from the nostril through which it has been exhaled previously. Due to use of alternate nostril, it is named as "Alternate Nostril Breathing".

It is supposed to be of great importance for our overall health. It is based on the basic presumption that at a time only one of our two nostrils remain active. This breathing type helps thorough cleansing of our nasal tract and its continuation to the lungs. It cures simple upper respiratory tract infections and oxygenates the blood properly. Its rate and rhythm can be varied easily by the person. It instantly gives a feeling of freshness and wellbeing. It is advised to do Anulom Vilom at least for 10 minutes every day for its gainful benefit. It should be learnt suitably before practicing. The rate of inspiration and exhalation are similar and can be modified by the person at his will. Anulom Vilom is a specialized breathing giving peace, calmness and good exercise.

\section{Bhramari (Humming Bee) Pranayam}

It is the slow exhalation from the nose with mouth closed, after a deep inhalation, creating a humming sound from the closed mouth. In its modified form, exhalation can also be done through the softly closed mouth and creating a sound of 'Ohm' continuously. It should be done at least for 5 times. This is supposed to help in concentration and relaxation after doing vigorous bhastrika, anulom vilom and kapalbhati breathing exercises.

\section{Ujjayi (Victorious) Pranayama}

It is a technique that helps calm the mind and warm the body. In this breathing, deep inhalation is done, and with slightly contracting the throat, the air is exhaled out through the nose. This breathing technique is used throughout Ashtanga and Vinyasa yoga practices. It is supposed to be useful for correcting hormonal imbalance.

\section{Tribandha Pranayama}

It is special pranayama, in which air is exhaled out forcefully and breath is held. Then perineal muscles are contracted (mula bandh), followed by upper abdominal muscles contraction (uddiyana bandh), and chin is lowered down contracting neck muscles (jalandhara bandh), causing tribandha. It is held as such for a half to 1 minute, and then air is inhaled deeply, and all the three contracted group of muscles are relaxed, releasing the tribandha. It can be repeated a few times. It is necessary to learn and do it under supervision before independent execution.

\section{Surya Bhedan Pranayama (Right Nostril Breathing)}

It is a type of breathing in which inspiration is done from the right nostril only and expiration is done from the left side. Its repetition is done in the same way. It is different from anulom vilom, in which both the nostrils are used alternatively for inspiration and expiration. It increases the metabolism and helps in weight loss.

\section{Sitali Pranayama (The Cooling Breath,} Purses Lip Breathing)

In this type of breathing, inhalation is done through the mouth, while rolling the tongue into semi-tubular shape. The air going in causes a cooling and calming effect on the nervous system. Expiration is done from both the nostrils.

The above breathing types are commonly practiced types. There are many other types serving specific function. Breathing exercises in combination with Asanas and dhyan provide complete route to positive health. A combination of all the three components in proper proportion is fruitful for overall benefit.

Pranayama means control of our life force using various breathing exercises, dhyana and concentration. It harnesses the power of human brain to a higher degree. It requires to be done initially under the supervision of the trainer or Guru to avoid mistakes in technique and obtain the maximum benefits. Ujjayi (victorious) pranayama and tribandha pranayama should be learned and practiced before doing independently. Other types of breathing exercises may be learned relatively easily. These breathing exercises are maximally beneficial on doing these regularly, and for adequate time. For a normal person of either sex exercises like, equal breathing, clavicular breathing, costal breathing, diaphragmatic breathing (kapalbhati), alternate nostril breathing (anulom vilom) and bhramari pranayam for adequate duration regularly helps in disease prevention and positive health maintenance. Due to simultaneous diet control, better oxygenation of body cells and positive thought process, these are supposed to prevent genesis of cancerous growth also.

Breathing exercises and Pranayama also help in rehabilitation of person suffering from physical or mental illness. Due to various physical postures adopted, joints become lax and mobile. Physical exercises can be done better and strength \& range of movement can be gained easily. Due to the calming effect on mind mental status and concentration also improves. Sambhavi mahamudra 
Kriya is especially useful in controlling behaviour of psychiatric patients.

\section{DISCUSSION}

Yoga is a multi-faceted spiritual tool with enhanced health and well-being as one of its positive effects. Components of yoga are Asana (physical postures), Pranayama (regulated breathing), and Meditation. Yoga interventions are equal or superior to other physical exercises in most outcome measures. Breathing regulation and mindfulness during yogic practice and maintenance of postures characterize yoga practices and make it distinct from other physical exercise modalities. ${ }^{11}$

Pranayama is considered as an add-on-therapy to 'Pharmacologically recommended treatment' of childhood Asthma. In chronic asthma cases, many studies have noted improvement in "Quality of life and change in asthma symptoms. $^{2}$ Modifications in breathing reduce hyperventilation and help normalization of the $\mathrm{CO} 2$ level. It also causes a reduction in bronchospasm and restlessness. Relaxation achieved by proper breathing decreases anxiety, improves the immunological parameters and endurance of respiratory muscles. ${ }^{3}$ In cases of chronic obstructive pulmonary diseases after 12 weeks of pranayama, parameters like 6 MWD (Minute Walk Distance) and LFT (Lung Function Tests) showed significant improvement. In this study, pranayama training was given by a layperson only [4] Diaphragmatic breathing and Shitali pranayama (pursed-lip breathing) done 10 minutes every day have been noted to improve breathing, daily activity levels, and decrease the use of a rescue inhaler. Breathing exercises have been taken as a complementary treatment in asthmatic patients. ${ }^{5}$

Yoga therapies are noted to improve the quality of life, decreased inflammatory markers, and helped peak-maximal oxygen intake in heart failure patients with a reduced ejection fraction. ${ }^{12}$ Pranayama with slower rhythm and manipulation of the nostrils mainly with breaths by the left nostril have shown a significant reduction in blood pressure in both acute and chronic cases, in 13 trials. In acute cases, there was a reduction of $20-30 \mathrm{mmHg}$ of mean systolic blood pressure (SBP), and $1 \mathrm{mmHg}$ of diastolic blood pressure (DBP). In chronic hypertension patients, a reduction of $4-20 \mathrm{mmHg}$ in SBP and $4-7 \mathrm{mmHg}$ in DBP was noted. ${ }^{8}$

Pranayama along with breathing exercises has been effective in the treatment of mood disorders and stress. A special yogic practice "Sambhavi Mahamudra Kriya," including both deep breathing and meditation technique, done for 21 minutes daily for 6 weeks, reduced the level of stress, and improved general well-being, compared to baseline in 142 individuals. ${ }^{13}$ Yoga brings about an integration of mind, body, and soul. Mindfulness (dhyana) emphasizes on focused awareness and accepting the internal experiences, without being judgmental. Due to the calming effect of Dhyana and meditation, along with relaxation achieved after various physical postures and breathing, yoga therapy has been found ameliorating, and as add-on therapy in severe mental illnesses like schizophrenia, bipolar and depressive disorders. ${ }^{14}$

A stressful lifestyle and unhealthy dietary habits lead to acidity and Gastro-Esophageal Reflux Disease (GERD). Diaphragmatic breathing exercises have been found to reduce belching and dyspepsia in these cases. ${ }^{15,16}$ Breathing exercises have been found beneficial in sickle cell disease patients as these help in utilizing more lung capacity and better oxygenation. ${ }^{17}$ The breathing exercise program for elderly patients undergoing spinal surgery was found to enhance their breathing exercise compliance, daily life satisfaction in addition to reducing their pulmonary infection rates, in a comparative study. ${ }^{18}$ In chronic low back pain patients, diaphragmatic breathing exercises have shown statistically significant improvement in maximal inspiratory pressure, chest excursion, and peak expiratory flow. ${ }^{19}$ With increasing scientific research in yoga, its therapeutic aspects are also being explored. Yoga is reported to reduce stress and anxiety, improves autonomic functions by triggering neurohormonal mechanisms by the suppression of sympathetic activity, and even, now-a-days, several reports suggested that yoga is beneficial for physical health of cancer patients. Such global recognition of yoga also testifies to India's growing cultural influence. ${ }^{20}$

In the present scenario of the Covid-19 pandemic, the involvement of the lungs leads to rapid deterioration of the patient's condition, leading to decreased vital capacity and blood oxygenation. Regular breathing exercises causing full expansion of all parts of the lung and pliability of alveoli is necessary to avoid the grave complication of the condition. Pranayama, particularly thoracic breathing, diaphragmatic breathing, equal breathing, alternate nostril breathing, Kapalbhathi, and cooling breathing are all types helpful for maintaining lung functions. The Chinese system of breathing exercises known as Qigong is similar to our pranayama and breathing exercises. It has been found effective in the prevention, treatment, and rehabilitation of Covid-19 patients in the elderly age group. ${ }^{10}$ In a study done on police trainees, yoga has shown encouraging results. Police trainees showed beneficial effects of yoga training, although they were undergoing intensive police training and the yoga training was relatively less intense. A shortening of visual reaction time and a decrease in red-green discriminatory reaction time was noted. They also showed a decrease in resting EMG voltage, signifying better muscular relaxation following pranayama training. A combination of Asan and Pranayama training for 6 months produced an improvement in motor and sensory nerve conduction. Total power of EEG, alpha and theta power as well as delta \% increased, while reaction time decreased signifying an alert and yet relaxed state of the neuromuscular system. ${ }^{21}$ Yoga is found to have effects on almost all our body systems including reproductive organs. Role of yogic exercises has been studied on male reproductive systems also. ${ }^{22}$ Sukha pranayama has been noted to give immediate relief in patients of hypertension. ${ }^{23}$ Mental and visual alertness improvement has been seen on yogic practices regular practice. Thus, literature supports positive effects of yoga and pranayama on various body systems. Still more scientific studies need to be conducted to show objectively measured effects.

\section{CONCLUSIONS}

Breathing exercises described under Indian Yogic practices are very effective in maintaining proper physical, mental and social health. These breathing exercises have been found to be effective as add-on therapy in acute asthma, COPD, chronic 
hypertension, psychiatric disorders, GERD, and post-operative cases of head \& neck, cardiovascular and upper abdominal ailments. It has proved its preventive and therapeutic effect in Covid-19 cases also. More scientific and comparative studies are needed to establish the definite role of Pranayama as a complementary mode of treatment in various conditions. Breathing exercises help in disease prevention and maintenance of positive state of health.

\section{Clinical Message}

Breathing exercises or Pranayama must be done by persons of all ages for maintenance of good health, prevention of diseases, and reduction in the symptoms of various medical and post-op conditions. Exercises should include its various types, and the time duration should be between 20 - 30 minutes every day.

Financial or other competing interests: None.

Disclosure forms provided by the authors are available with the full text of this article at jemds.com.

\section{REFERENCES}

[1] Dasari V, Dasari K. Nutraceutical to support immunity: COVID-19 pandemic - a wake-up call. Journal of Clinical and Diagnostic Research 2020;7(14):OE05-0E09.

[2] Das RR, Sankar J, Kabra SK. Role of breathing exercises and yoga/pranayama in childhood asthma: a systematic review. Current Pediatric Reviews 2019;15(3):175-83.

[3] Sankar J, Das RR. Asthma-a disease of how we breathe: role of breathing exercises and pranayama. The Indian Journal of Pediatrics 2018;85(10):905-10.

[4] Kaminsky DA, Guntupalli KK, Lippmann J, et al. Effect of yoga breathing (Pranayama) on exercise tolerance in patients with chronic obstructive pulmonary disease: a randomized, controlled trial. The Journal of Alternative and Complementary Medicine 2017;23(9):696-704.

[5] Karam M, Kaur BP, Baptist AP. A modified breathing exercise program for asthma is easy to perform and effective. Journal of Asthma 2017;54(2):217-22.

[6] Grams ST, Ono LM, Noronha MA, et al. Breathing exercises in upper abdominal surgery: a systematic review and meta-analysis. Rev Bras Fisioter 2012;16(5):345-53.

[7] Moradian ST, Heydari AA, Mahmoudi H. What is the role of preoperative breathing exercises in reducing postoperative atelectasis after CABG? Reviews on Recent Clinical Trials 2019;14(4):275-9.

[8] Brandani JZ, Mizuno J, Ciolac EG, et al. The hypotensive effect of Yoga's breathing exercises: a systematic review. Complementary Therapies in Clinical Practice 2017;28:38-46.

[9] Gen AÇ, Ikiz AO, Günerli EA, et al. Effect of deep breathing exercises on oxygenation after major head and neck surgery. Otolaryngology-Head and Neck Surgery 2008;139(2):281-5.

[10] Feng F, Tuchman S, Denninger JW, et al. Qigong for the prevention, treatment, and rehabilitation of COVID-19 infection in older adults. The American Journal of Geriatric Psychiatry 2020;28(8):812-9.

[11] Govindaraj R, Karmani S, Varambally S, et al. Yoga and physical exercise-a review and comparison. International Review of Psychiatry 2016;28(3):242-53.

[12] Lopes CP, Danzmann LC, Moraes RS, et al. Yoga and breathing technique training in patients with heart failure and preserved ejection fraction: study protocol for a randomized clinical trial. Trials 2018;19(1):405.

[13] Peterson CT, Bauer SM, Chopra D, et al. Effects of shambhavi mahamudra kriya, a multicomponent breathbased yogic practice (Pranayama), on perceived stress and general well-being. Journal of Evidence-Based Complementary \& Alternative Medicine 2017;22(4):78897.

[14] Sathyanarayanan G, Vengadavaradan A, Bharadwaj B. Role of yoga and mindfulness in severe mental illnesses: a narrative review. International Journal of Yoga 2019;12(1):3-28.

[15] Ong AM, Chua LT, Khor CJ, et al. Diaphragmatic breathing reduces belching and proton pump inhibitor refractory gastroesophageal reflux symptoms. Clinical Gastroenterology and Hepatology 2018;16(3):407-16.e2.

[16] Qiu K, Wang J, Chen B, et al. The effect of breathing exercises on patients with GERD: a meta-analysis. Annals of Palliative Medicine 2020;9(2):405-13.

[17] Matthie N, Brewer CA, Moura VL, et al. Breathing exercises for inpatients with sickle cell disease. Medsurg Nursing: official Journal of the Academy of Medical-Surgical Nurses 2015;24(1):35-8.

[18] Jo HM, Shin H. Effect of breathing exercise using panflutes on the postoperative compliance, pulmonary infections and life satisfaction in elderly patients undergoing spinal surgery. Journal of Korean Academy of Nursing 2018;48(3):279-88.

[19] Finta R, Boda K, Nagy E, et al. Does inspiration efficiency influence the stability limits of the trunk in patients with chronic low back pain? Journal of Rehabilitation Medicine 2020;52(3):jrm00038.

[20] Sengupta P. Health impacts of yoga and pranayam: a state of the art review. Int J Prev Med 2012;3(7):444-58.

[21] Trakroo M, Bhavanani AB, Pal GK, et al. A comparative study of the effects of asan, pranayama and asanpranayama training on neurological and neuromuscular functions of Pondicherry police trainees. Int J Yoga 2013;6(2):96-103.

[22] Sengupta $P$, Chaudhary $P$, Bhattacharya K. Male reproductive health and yoga. Int J Yoga 2013;6(2):87-95.

[23] Bhavnani AB, Sanjay Z, Madanmohan. Immediate effect of Sukha Pranayama on cardiovascular variables in patients of hypertension. Int J Yoga Therap 2011;(21):73-6. 